\title{
MHD heat transfer flow of Casson fluid past a stretching wedge subject to suction and injection
}

\author{
Imran Ullah ${ }^{\mathrm{a}}$, Sharidan Shafie ${ }^{\mathrm{a},{ }^{*}}$, Ilyas Khan ${ }^{\mathrm{b}}$ \\ a Department of Mathematical Sciences, Faculty of Science, Universiti Teknologi Malaysia, 81310 UTM Johor Bahru, Johor, Malaysia \\ b College of Engineering, Majmaah Univerisity, Majmaah, Saudi Arabia \\ * Corresponding author: sharidan@utm.my
}

\section{Article history}

Received 6 September 2017

Accepted 17 November 2017

\begin{abstract}
The steady two dimensional incompressible hydromagnetic boundary layer flow caused by stretching wedge immersed in Casson fluid with heat transfer and suction/injection is investigated numerically. The governing nonlinear partial differential equations are transformed into nonlinear ordinary differential equations using suitable transformations and then solved numerically via Keller-box method. Numerical results for local skin friction coefficient are compared with the existing literature and observed in closed agreement with those results. The effects of pertinent parameters on flow fields are displayed graphically and discussed. It is found that velocity decreases with increase of Casson parameter and wedge angle parameter when the wedge is stretching faster than free stream. It is also observed that rate of heat transfer at surface increases with the increase of Prandtl number and Casson fluid parameter. Moreover, with increase of suction parameter the fluid velocity decreases and rate of shear stress increases.
\end{abstract}

Keywords: Casson fluid; stretching wedge; MHD; Keller-box

\section{INTRODUCTION}

In the recent years, the study of non-Newtonian fluids has attracted the attentions of researchers due to its wide range applications in engineering and industry. Due to the complexity in the governing equations of these fluids, not a single equation exists that exhibit the properties of these fluids. For this purpose, several models have been proposed in this regard. In the existing literature, power law model and Maxwell model are commonly used for non-Newtonian fluids. There is another non-Newtonian model, known as Casson model. This model was developed by (Casson, 1959) for preparation of printing inks and silicon suspensions. Many researchers agree that it is the best fit to rheological data. Furthermore, it is presentable rheological model for blood and chocolate. Casson fluid exhibits yield stress. The fluid behaves like solid if the applied shear stress is less than yield stress whereas for greater shear stress, it starts moving (Eldabe and Salwa, 1995; Dash et al., 1996).

The wedge problem was first solved by (Falkner and Skan, 1931). They obtained the numerical solutions using the similarity transformations. Later on, many researchers (Ishak et al., 2007; Yacob et al., 2011; Postelnicu and Pop, 2011) have extended this pioneer work for different types of fluids. In Casson fluid, the two dimensional boundary layer flow of Casson fluid over a symmetric wedge was studied by (Mukhopadhyay et al., 2013). Later, (Mukhopadhyay and Mandal, 2014) extended the work of (Mukhopadhyay et al., 2013) and considered the permeable wedge with constant surface heat flux. They observed that the fluid velocity increased with an increase in Casson parameter. The effect of thermal radiations on Falkner-Skan flow of Casson fluid over a moving wedge was investigated by (Raju and Sandeep, 2016). They assumed that the wedge is flowing in the nanofluid.

Besides this, many researchers focused on the study of magnetohydrodynamic (MHD) boundary layer flow. The problems with magnetic field play a vital role in many industrial applications such as MHD pumps, MHD power generators, geothermal systems, blood flow measurement, and construction of heat exchangers. The hydromagnetic flow of viscous fluid over a non-isothermal static wedge was analyzed by (Yih, 1999). The effects of thermal radiation on MHD flow of Newtonian fluid was explored by (Chamkha et al., 2003). The two dimensional mixed convection flow of electrically conducting flow due to a porous stretching wedge is presented by ( $\mathrm{Su}$ et al., 2012). MHD forced convection flow of nanofluid over a stationary wedge was developed by (Chamkha and Rashad, 2014). The unsteady electrically conducting flow of micropolar fluid over permeable wedge with convective boundary condition was reported by (Alam et al., 2015). (El-Dabe et al., 2015) investigated the effect of magnetic field on heat and mass transfer flow of Casson fluid generated by moving wedge.

In the above mentioned study, mostly the wedge is either static or moving. Very less attention is paid towards the Casson flow over stretching wedge. To the best of authors' knowledge, no attempt is made so far to analyze the effects of magnetic field on Casson flow over a porous stretching wedge. The aim of present study is to investigate the effects of suction injection on heat transfer flow of Casson fluid caused by stretching wedge under the influence of magnetic field. The non-linear governing equations are transformed into non-linear ordinary differential equations using similarity transformations and then solved numerically by Keller- box method (Cebeci and Bradshaw, 1988). 


\section{MATHEMATICAL FORMULATION}

Consider incompressible flow of Casson fluid over a porous stretching wedge in the presence of applied magnetic field $B(x)=B_{0} x^{\frac{m-1}{2}}$ with $B_{0}$ is the strength of magnetic field. The induced magnetic field is neglected due to low magnetic Reynolds number. The wedge is stretched with velocity of $u_{w}(x)=\gamma u_{e}(x), \gamma \geq 0$ and the free stream velocity $u_{e}(x)=U_{\infty} x^{m}$, where $m 0 \leq m \leq 1$ and $U_{\infty}$ are constants (see Fig. 1). $\lambda=\frac{2 m}{m+1}$ is the wedge angle parameter that correspond to $\Omega=\lambda \pi$ for the total angle of the wedge. The temperature at boundary wall and free stream are denoted by the constants $T_{w}$ and $T_{\infty}$.

$$
\begin{aligned}
& \frac{\partial u}{\partial x}+\frac{\partial u}{\partial y}=0 \\
& u \frac{\partial u}{\partial x}+v \frac{\partial u}{\partial y}=u_{e} \frac{\partial u_{e}}{\partial x}+v\left(1+\frac{1}{\beta}\right) \frac{\partial^{2} u}{\partial y^{2}}+\frac{\sigma B^{2}(x)}{\rho}\left(u_{e}-u\right) \\
& u \frac{\partial T}{\partial x}+v \frac{\partial T}{\partial y}=\frac{k}{\rho c_{p}} \frac{\partial^{2} T}{\partial y^{2}}
\end{aligned}
$$

where $u$ and $v$ represent the velocity components in $x$ and $y$ directions respectively, $v$ is kinematic viscosity, $\sigma$ is the electrically conductivity, $\rho$ is the fluid density, $T$ is the fluid temperature, $\beta$ is the Casson parameter, $k$ is the thermal conductivity of the fluid and $c_{p}$ is the specific heat at constant pressure.

The corresponding boundary conditions are

$u=u_{w}(x)=\gamma u_{e}(x), v=v_{w}(x), T=T_{w}$ at $y=0$

$u=u_{e}(x), T \rightarrow T_{\infty}$ as $y \rightarrow \infty$

where $v_{w}(x)=V_{0} \sqrt{x^{m-1}}$ is the velocity at the wall with constant $V_{0}$. Here $v_{w}(x)>0$ is the injection velocity and $v_{w}(x)<0$ is the suction velocity, respectively. The constant parameter $\gamma=\frac{U_{w}}{U_{\infty}}$ is velocity ratio parameter of wedge such that $\gamma>1$ corresponds to faster stretching of wedge than that of free stream and $\gamma<1$ corresponds to slower than that of free stream flow.

Now introducing the following similarity transformations

$\Psi=\sqrt{\frac{2 v x u_{e}}{m+1}} f(\eta), \eta=\sqrt{\frac{(m+1) u_{e}}{2 v x}} y, \theta=\frac{T-T_{\infty}}{T_{w}-T_{\infty}}$

where the stream function $\Psi$ is defined by the following relations:

$$
u=\frac{\partial \Psi}{\partial y}, v=-\frac{\partial \Psi}{\partial x}
$$

From Eqs. $(2-5)$, one arrives at the following non-dimensional system

$\left(1+\frac{1}{\beta}\right) f^{\prime \prime \prime}+f f^{\prime \prime}+\lambda\left(1-f^{2}\right)-M\left(f^{\prime}-1\right)=0$

$\theta^{\prime \prime}+\operatorname{Pr} f \theta^{\prime}=0$

$f(0)=S, f^{\prime}(0)=\gamma, \theta(0)=1$

$f^{\prime}(\infty)=1, \theta(\infty)=0$

where $M=\frac{\sigma B_{0}{ }^{2}}{\rho U_{\infty}(m+1)}$ is the magnetic field parameter, $\operatorname{Pr}={ }_{k}^{\overline{\mu c_{p}}}$ is the Prandtl number and $S=\frac{-\sqrt{2} V_{0}}{\sqrt{U_{\infty} v(m+1)}}$ is the suction/injection parameter such that $S(>0)$ is suction velocity $S(<0)$ is injection velocity and $S(=0)$ represents impermeable wedge
The parameters with physical interests are the skin friction coefficient $C f_{x}$ and local Nusselt number $N u_{x}$ which are defined as follows:

$$
\left.\begin{array}{c}
C f_{x}\left(R e_{x}\right)^{1 / 2} \sqrt{\frac{2}{m+1}}=\frac{\tau_{w}}{\rho u_{e}^{2}}=\left(1+\frac{1}{\beta}\right) f^{\prime \prime}(0) \\
N u_{x}\left(R e_{x}\right)^{-1 / 2} \sqrt{\frac{2}{m+1}}=\frac{x q_{w}}{k\left(T_{w}-T_{\infty}\right)}=-\theta^{\prime}(0)
\end{array}\right\}
$$

where $\tau_{w}$ is the wall skin friction, $q_{w}$ is the wall heat flux and $R e_{x}=\frac{x u_{e}}{v}$ is the local Reynold number.

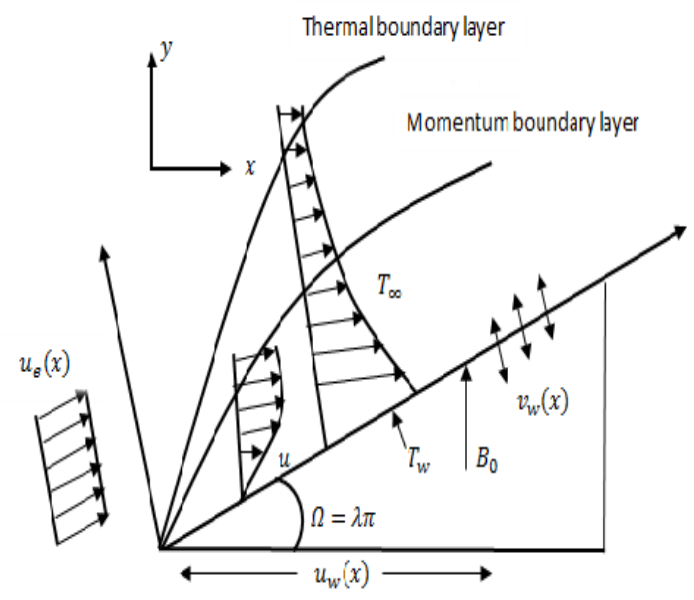

Fig. 1 Sketch of physical problem and coordinate system.

\section{RESULTS AND DISCUSSION}

In order to visualize the behavior of physical parameters, numerical computations are carried out for various values of Casson fluid parameter $\beta$, magnetic parameter $M$, stretching wedge parameter $\gamma$, Prandtl number $\operatorname{Pr}$ and suction/injection parameter $S$.

The accuracy of present results are validated through comparisons with the results of (Yih, 1999), (Ishak et al., 2007) and (Ahmad and Khan, 2013), and are presented in Table 1. Comparisons are observed in close agreement with those results.

Table 1 Comparison of the coefficient of skin friction $f^{\prime \prime}(0)$ with various values of $S$ for $M=\gamma=0, \lambda=1$ and $\beta \rightarrow \infty$

\begin{tabular}{|c|c|c|c|c|}
\hline \multicolumn{5}{|c|}{$-f^{\prime \prime}(0)$} \\
\cline { 1 - 1 } & $\begin{array}{c}\text { Yih } \\
(1995)\end{array}$ & $\begin{array}{c}\text { Ishak et al. } \\
(2007)\end{array}$ & $\begin{array}{c}\text { Ahmad and Khan } \\
(2013)\end{array}$ & $\begin{array}{c}\text { Present } \\
\text { results }\end{array}$ \\
\hline-1 & 0.75658 & 0.7566 & 0.75655 & 0.7566 \\
\hline-0.5 & 0.96923 & 0.9692 & 0.96922 & 0.9692 \\
\hline 0 & 1.23259 & 1.2326 & 1.23258 & 1.2326 \\
\hline 0.5 & 1.54175 & 1.5418 & 1.54175 & 1.5418 \\
\hline 1 & 1.88931 & 1.8893 & 1.88931 & \\
\hline
\end{tabular}

Figures (2-4) demonstrate the effects of $\beta, M$ and $S$ on velocity profile, respectively. It is worth to be mentioned that the present phenomenon reduces to Newtonian fluid for large $\beta$ i.e. $\beta \rightarrow \infty$. From Fig. 2, it is noticed that fluid velocity drops with increment in $\beta$ when $\gamma>1$ whereas fluid velocity rises with $\beta$ when $\gamma<1$. In other words, the absolute values of shear stress increase with the increase of $\beta$ and 
momentum boundary layer thickness reduces for $\gamma>1$ or $\gamma<1$. The reason is that increase in $\beta$ reduces the yield stress. Consequently, the boundary layer thickness decreases. It is also observed that shear stress rate becomes zero when $\gamma=1$ and fluid velocity is uniform. Moreover, the velocity has inverted boundary layer pattern for $\gamma<1$. In this case, the velocity of stretching wedge is excited via free stream velocity.

Fig. 3 shows that increase in $M$ declines the fluid velocity when $\gamma>1$ whereas fluid velocity enhances with $M$ when $\gamma<1$. However, the momentum boundary layer thickness reduces with $M$ in both cases of $\gamma$. Physically, the influence of magnetic field produces a strong drag force, and resulting slow down the fluid flow across the boundary.

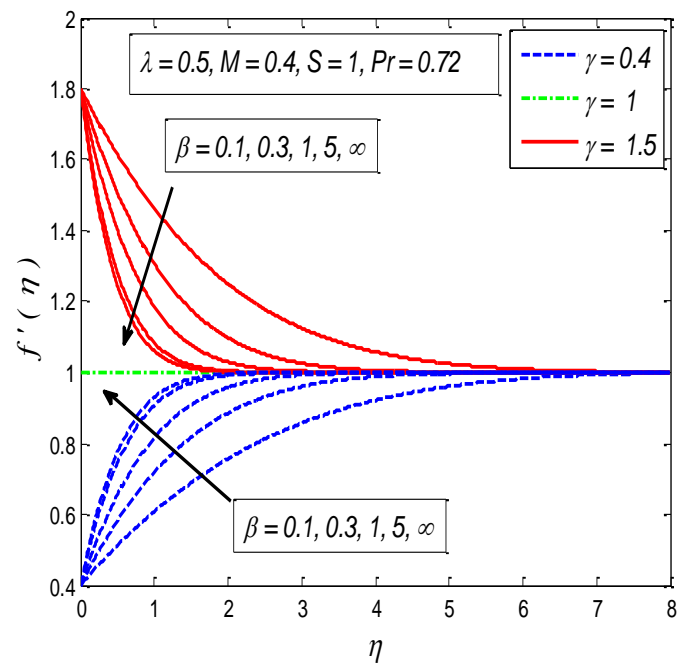

Fig. 2 Effect of $\beta$ on velocity for various $\gamma$

From Fig. 4, it is noticed that in the case of $\gamma>1$ fluid velocity falls when $S>0$ and increases when $S<0$ whereas, reverse trend is observed in the case of $\gamma<1$ when $S$ increased. It is well known fact that flow experiences a resistance due to wall suction, due to which momentum boundary layer thickness reduces.

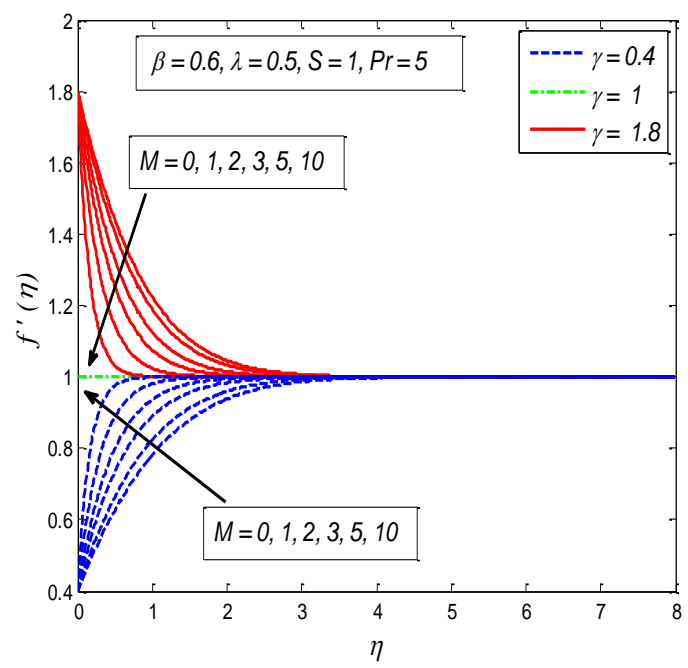

Fig. 3 Effect of $M$ on velocity for different $\gamma$

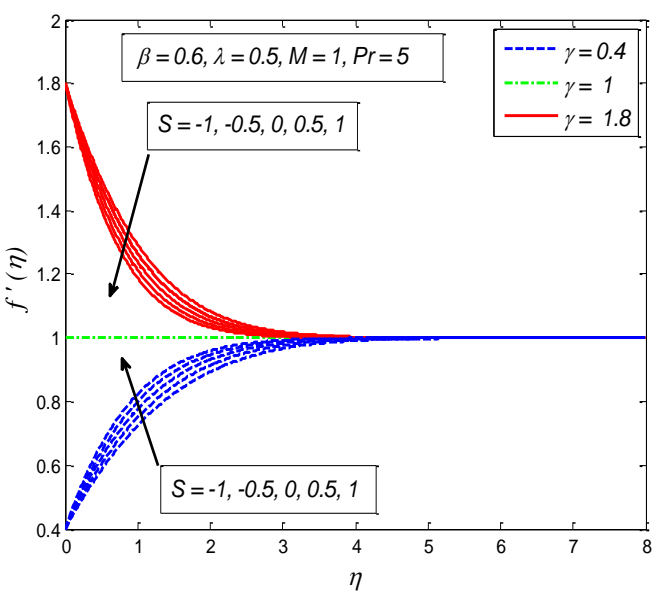

Fig. 4 Effect of $S$ on velocity for different $\gamma$

The effects of $\beta, M, S$ and $\operatorname{Pr}$ on dimensionless temperature, respectively are shown in Figures (5-8). Fig. 5 reveals that dimensionless temperature reduces with increase of $\beta$ when $\gamma<1$ whereas temperature of fluid enhances with $\beta$ when $\gamma>1$.

Fig. 6 explores that dimensionless temperature drops as $\mathrm{M}$ increases when $\gamma<1$ and as $\gamma>1$ the temperature starts increasing with $M$. Fig. 7 explores that temperature drops in the case of suction whereas injection excites the fluid temperature for both $\gamma>1$ and $\gamma<1$. In fact, the rate of heat transfer enhances when suction occurs at wall.

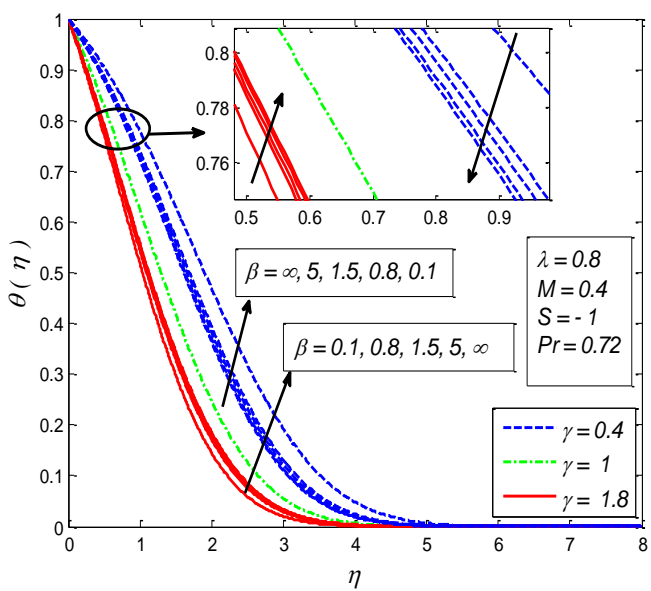

Fig. 5 Effect of $\beta$ on temperature for different $\gamma$

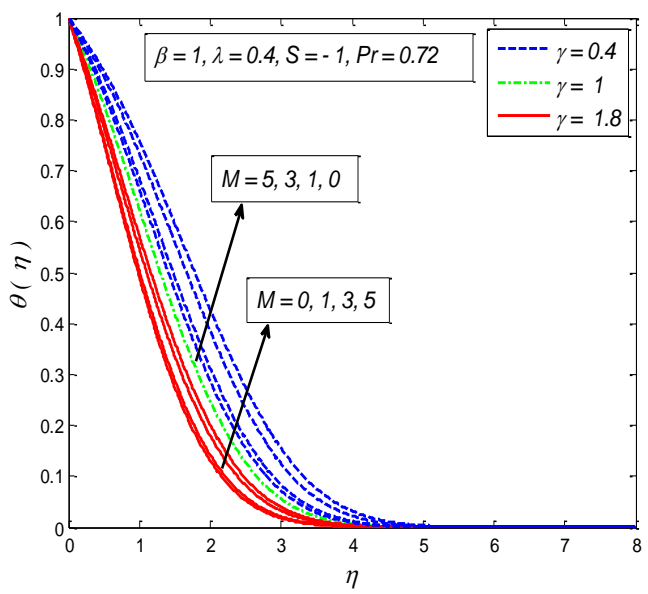

Fig. 6 Effect of $M$ on temperature for different $\gamma$ 
Fig. 8 illustrates that the strength of Prandtl number tends to decline the thermal boundary layer thickness. As increasing values of $\mathrm{Pr}$ tend to reduce the thermal diffusivity of fluid, and the thermal boundary layer becomes thinner.

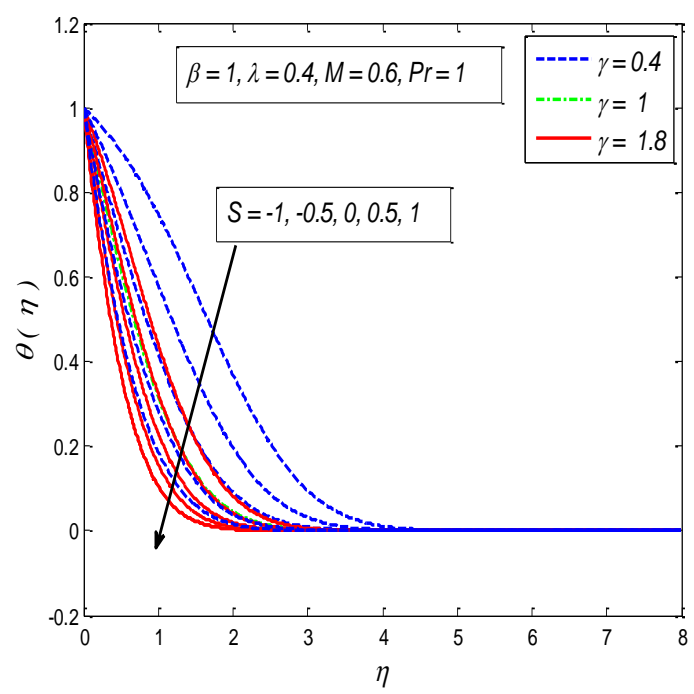

Fig. 7 Effect of $S$ on temperature for different $\gamma$

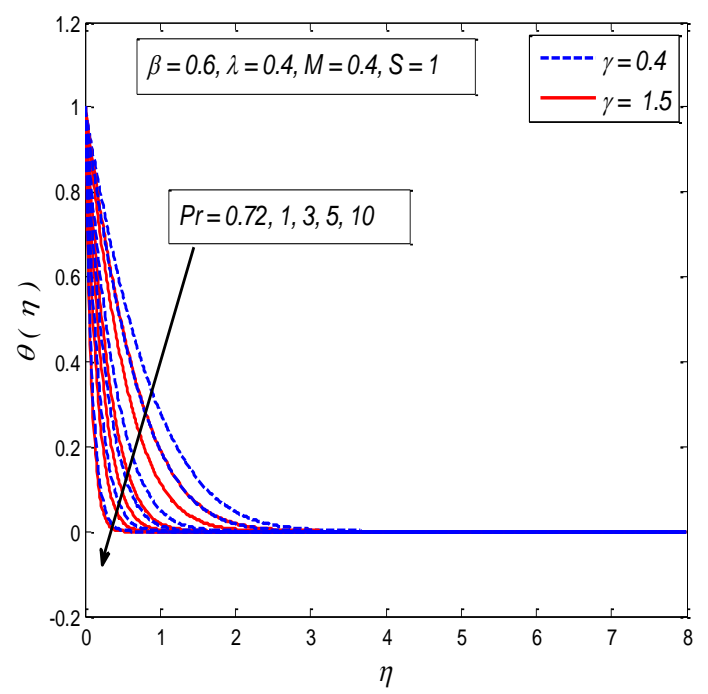

Fig. 8 Effect of $\operatorname{Pr}$ on temperature for different $\gamma$

Figures 9 and 10 portray the variation of skin friction coefficient and rate of heat transfer for different values of $\beta, \gamma, \lambda, \operatorname{Pr}$ and $S$, respectively. From Fig. 9 it is noticed that skin friction coefficient increases with the increase of $\beta$ whereas reduces with increase of $S$ when $\gamma>1$.

From Fig. 10, it is noticeable that rate of heat transfer at surface is an increasing function of $\operatorname{Pr}$ and $\beta$ when $\gamma<1$ whereas rate of heat transfer lower with increase of $\beta$ when $\gamma>1$. On the other hand, the case of $\gamma<1$ is opposite to this. It is also found that skin friction is zero when $\gamma=1$.

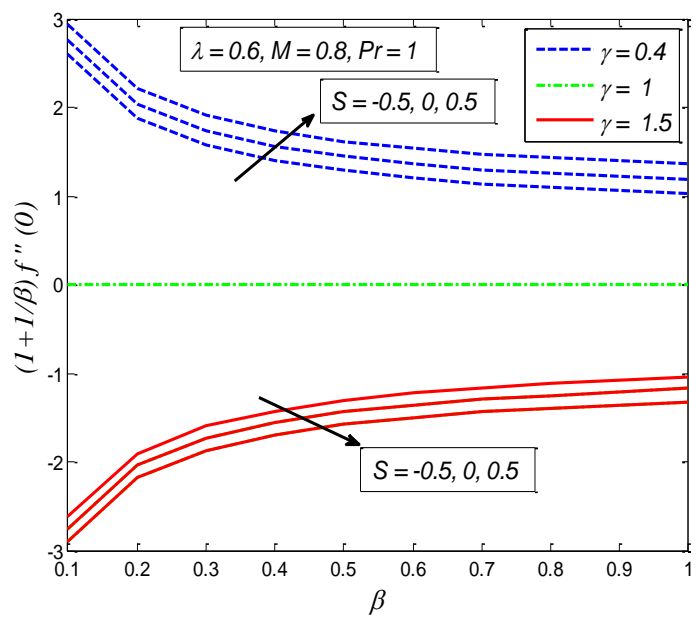

Fig. 9 Variation of skin friction coefficient for various $\beta, \gamma$, and $S$

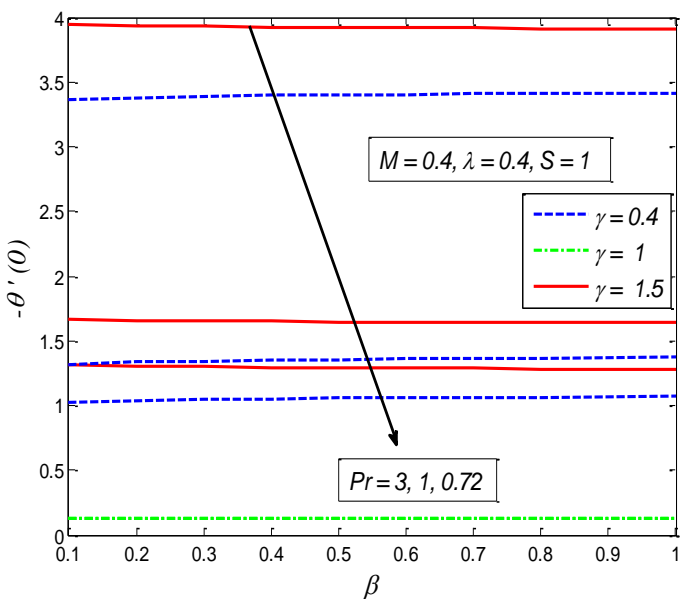

Fig. 10 Variation of Nusselt number for various $\beta, \gamma$, and $P r$

\section{CONCLUSION}

In this paper, the steady state two dimensional electrically conducting flow of Casson fluid with characteristic of heat transfer past a permeable stretching wedge is discussed. The non-linear partial differential equations are converted into non-linear ordinary differential equations using suitable transformations, and then solved numerically by Keller-box method. The results are compared with the results of available literature and found in good agreement. Effects of Casson parameter $\beta$, magnetic parameter $M$, Prandtl number $P r$ and suction/injection parameter $S$ are presented graphically with the following key points:

- Fluid velocity declines with increment in $\beta$ and $S$ when $\gamma>1$ whereas enhances when $\gamma<1$.

- The dimensionless temperature drops with an increase in $\beta$ and $M$ when $\gamma<1$.

- The shear stress rate is observed higher for lager values of $\beta$ when $\gamma>1$.

- The heat transfer rate rises with increase in $\operatorname{Pr}$ and $\beta$ when $\gamma<$ 1. 


\section{ACKNOWLEDGEMENT}

The authors would like to acknowledge Ministry of Higher Education (MOHE) and Research Management Centre Universiti Teknologi Malaysia (UTM) for the financial support through vote numbers $4 \mathrm{~F} 713$ and $13 \mathrm{H} 74$ for this research..

\section{REFERENCES}

Ahmad, R. and Khan, W. A., 2013. Effect of viscous dissipation and internal heat generation/absorption on heat transfer flow over a moving wedge with convective boundary condition. Heat Transfer-Asian Research, 42(7), pp.589-602.

Alam, M., Islam, T. and Rahman, M., 2015. Unsteady hydromagnetic forced convective heat transfer flow of a micropolar fluid along a porous wedge with convective surface boundary condition. International Journal of Heat and Technology, 33(2), pp.115-122.

Casson, N. 1959. A flow equation for pigment-oil suspensions of the printing ink type. In: Mill, C.C., Ed., Rheology of Disperse Systems, Pergamon Press, Oxford, pp.84-104.

Cebeci, T. and Bradshaw, P., 1988. Physical and computational aspects of convective heat transfer 1 st ed. New York: Springer.

Chamkha, A. J., Mujtaba, M., Quadri, A. and Issa, C. 2003. Thermal radiation effects on MHD forced convection flow adjacent to a non-isothermal wedge in the presence of a heat source or sink. Heat and Mass Transfer, 39, pp. 305-312.

Chamkha, A.J. and Rashad, A.M., 2014. MHD forced convection flow of a nanofluid adjacent to a non-isothermal wedge. Computational Thermal Sciences, 6(1), pp. 27-39.

Dash, K., Mehta, R. and Jayaraman, G., 1996. Casson fluid flow in a pipe filled with a homogeneous porous medium. International Journal of Engineering. Science, 34(10), pp.1145-1156.

Eldabe, N.T.M. and Salwa, M.G.E, 1995. Heat transfer of MHD nonnewtonian Casson fluid flow between two rotating cylinder. Journal of physical society Japan, 64, pp.41-64.

El-Dabe, N. T., Ghaly, A. Y. Rizkallah, R. R., Ewis, K. M. and Al-Bareda, A. S. 2015. Numerical solution of MHD boundary layer flow of nonNewtonian Casson fluid on a moving wedge with heat and mass transfer and induced magnetic field, Journal of Applied Mathematics and Physics, 3, pp.649-663.

Falkner, V.M. and Skan, S.W., 1931. Some approximate solutions of the boundary-layer equations. Philosophical Magzine, 12, pp.865-896.

Ishak, A., Nazar, R. and Pop, I., 2007. Falkner-Skan equation for flow past a moving wedge with suction or injection. Journal of Applied Mathematics and Computing, 25(1-2), pp.67-83.

Mukhopadhyay, S. and Mandal, I.C., 2014. Boundary layer flow and heat transfer of a Casson fluid past a symmetric porous wedge with surface heat flux. Chinese Physics B, 23(4), p.44702.

Mukhopadhyay, S., Mondal, I.C. and Chamkha, A.J., 2013. Casson fluid flow and heat transfer past a symmetric wedge. Heat Transfer-Asian Research, 42(8), pp.665-675.

Postelnicu, a. and Pop, I., 2011. Falkner-Skan boundary layer flow of a powerlaw fluid past a stretching wedge. Applied Mathematics and Computation, 217(9), pp.4359-4368.

Raju, C.S.K. and Sandeep, N., 2016. Nonlinear radiative magnetohydrodynamic Falkner-Skan flow of Casson fluid over a wedge. Alexandria Engineering Journal, 55(3), pp.2045-2054.

Su, X., Zheng, L., Zhang, X. and Zhang, J., 2012. MHD mixed convective heat transfer over a permeable stretching wedge with thermal radiation and ohmic heating. Chemical Engineering Science, 78, pp.1-8.

Yacob, N.A., Ishak, A., Nazar, R. and Pop, I., 2011. Falkner-Skan problem for a static and moving wedge with prescribed surface heat flux in a nanofluid. International Communications in Heat and Mass Transfer, 38(2), pp.149-153.

Yih, K.A., 1999. MHD forced convection flow adjacent to a non-isothermal wedge. International Communications in Heat and Mass Transfer, 26(6), pp.819-827. 